\title{
BMJ Open Long COVID and the role of physical activity: a qualitative study
}

\author{
Helen Humphreys (D , ${ }^{1,2}$ Laura Kilby, ${ }^{3}$ Nik Kudiersky, ${ }^{2}$ Robert Copeland ${ }^{1,4}$
}

To cite: Humphreys H, Kilby L, Kudiersky N, et al. Long COVID and the role of physical activity: a qualitative study. BMJ Open 2021;11:e047632. doi:10.1136/ bmjopen-2020-047632

- Prepublication history and additional material for this paper is available online. To view these files, please visit the journal online (http://dx.doi.org/10. 1136/bmjopen-2020-047632).

Received 07 December 2020 Revised 03 February 2021 Accepted 23 February 2021
Check for updates

(c) Author(s) (or their employer(s)) 2021. Re-use permitted under CC BY-NC. No commercial re-use. See rights and permissions. Published by BMJ.

${ }^{1}$ Advanced Wellbeing Research Centre, Sheffield Hallam University, Sheffield, UK ${ }^{2}$ Sport and Physical Activity Research Centre, Sheffield Hallam University, Sheffield, UK ${ }^{3}$ Centre for Behavioural Science and Applied Psychology, Sheffield Hallam University, Sheffield, UK

${ }^{4}$ National Centre for Sport and Exercise Medicine, Sheffield Hallam University, Sheffield, UK

Correspondence to

Dr Helen Humphreys;

H.Humphreys@shu.ac.uk

\section{ABSTRACT}

Objectives To explore the lived experience of long COVID with particular focus on the role of physical activity.

Design Qualitative study using semistructured interviews. Participants 18 people living with long COVID (9 men, 9 women; aged between 18-74 years; 10 white British, 3 white 0ther, 3 Asian, 1 black, 1 mixed ethnicity) recruited via a UK-based research interest database for people with long COVID.

Setting Telephone interviews with 17 participants living in the UK and 1 participant living in the USA.

Results Four themes were generated. Theme 1 describes how participants struggled with drastically reduced physical function, compounded by the cognitive and psychological effects of long COVID. Theme 2 highlights challenges associated with finding and interpreting advice about physical activity that was appropriately tailored. Theme 3 describes individual approaches to managing symptoms including fatigue and 'brain fog' while trying to resume and maintain activities of daily living and other forms of exercise. Theme 4 illustrates the battle with selfconcept to accept reduced function (even temporarily) and the fear of permanent reduction in physical and cognitive ability.

Conclusions This study provides insight into the challenges of managing physical activity alongside the extended symptoms associated with long COVID. Findings highlight the need for greater clarity and tailoring of physical activity-related advice for people with long COVID and improved support to resume activities important to individual well-being.

\section{INTRODUCTION}

As of January 2021, more than 93 million cases of COVID-19 have been reported worldwide. ${ }^{1}$ Although the majority of people infected recover within weeks, many people experience persistent symptoms, irrespective of age and underlying health conditions, termed 'long COVID'. ${ }^{3}$ Long COVID appears to be a multisystem disease associated with a complex array of respiratory, neurological, cardiovascular, gastrointestinal, musculoskeletal, rheumatological, dermatological and immunological symptoms ranging in severity, frequency and duration. ${ }^{3-6}$ Symptom surveillance surveys have reported estimates of long COVID (defined as symptoms lasting $\geq 12$ weeks) affecting $10 \%$ of people testing positive for COVID-19. ${ }^{7}$ Preliminary findings
Strengths and limitations of this study

- To our knowledge, this article is the first to explore the role of physical activity in the lived experience of long COVID using a qualitative approach.

- The study design enabled in-depth enquiry of lived experiences in a diverse sample.

- Inductive thematic analysis ensured descriptions and interpretations of the lived experience were tested and found to be grounded in the data.

- Participants were recruited from members of a long COVID research interest database who registered via an online form, meaning study findings might not capture the views of digitally excluded populations

from MRI investigations also show that $\sim 70 \%$ of 'low-risk' individuals testing positive for COVID-19 present signs of impairment in one or more organs 4 months after symptom onset. $^{8}$ In a recent survey, the three most debilitating symptoms of long COVID were identified as fatigue, shortness of breath and cognitive dysfunction. $89 \%$ of survey respondents also reported that mental and/ or physical exertion triggered the relapse of symptoms (postexertional malaise). ${ }^{4}$

Along with personal accounts, ${ }^{9}$ qualitative studies have provided valuable insight into the lived experience of long COVID. ${ }^{2} 1011$ People with long COVID describe an illness trajectory and heterogeneous symptomatology that did not conform to initial expectations and were not acknowledged in public health advice. ${ }^{21011}$ This has posed challenges for the medical profession, who have lacked evidence-based guidance to treat and support patients. Individual experiences of medical care have varied from well-meaning but inconclusive to disbelief. ${ }^{2} 1011$ This lack of understanding about long COVID extends beyond the medical and scientific communities to employers, family and friends, leaving many people feeling frustrated and isolated in their self-management efforts ${ }^{2} 1011$ and increasingly turning to online communities of people with long COVID for validation and advice. $^{2} 1011$ 
A commonly reported approach to self-management for long COVID is pacing. ${ }^{2911}$ This involves the strategic use of physical and mental energy reserves, with the aim of preventing or mitigating symptom flareups. ${ }^{12} 13$ Formal guidelines now include the Pace, Plan and Prioritise principles. ${ }^{12}{ }^{13}$ Nevertheless, the role of physical activity (PA) in the management and rehabilitation of long COVID remains unclear. It is hypothesised that persistent debilitating symptoms are caused by organ dysfunction induced by the virus, but symptoms are likely to be compounded by deconditioning as a result of sedentary behaviour. ${ }^{14-16}$ While it is evident that PA can exacerbate symptoms, it is unknown how PA influences the broader recovery trajectory and how individuals have managed this aspect of their recovery. This study explores the lived experience of people with long COVID-focusing on the role of PA-to inform the design and implementation of rehabilitation support.

\section{METHODS}

\section{Participants and recruitment}

Interviews were conducted with English-speaking adults aged $>18$ years who self-identified as recovering from COVID-19, were not hospitalised (did not receive inpatient treatment) and had experienced a recovery period lasting 3 weeks or more, a time frame consistent with definitions of 'postacute COVID-19' at the time of study initiation. ${ }^{17}$ Ethical approval was granted by Sheffield Hallam University. Participants were recruited from a COVID-19 research interest database (the RICOVR database) established by the Advanced Wellbeing Research Centre (AWRC) at Sheffield Hallam University. ${ }^{18}$ At the time of the study, 2022 people were registered on the AWRC database (see table 1 for characteristics). Consistent with other long COVID research, a positive COVID-19 test was not an inclusion criterion. ${ }^{1719}$

Purposive selection was used to ensure that the sample reflected a range of ages, genders and ethnicities. In accordance with UK demographic estimates, ${ }^{20}$ we aimed to recruit $15 \%$ of participants from black, Asian and minority ethnic groups and $85 \%$ from the white British population, with an even sex ratio. To achieve a widespread of ages, two to three participants were selected from each age category (18-24 years; 25-34 years; $35-44$ years; $45-54$ years; $55-64$ years; $\geq 65$ years). Database members were stratified by age group, gender and ethnicity, and then selected chronologically according to the date that they registered with the RICOVR database. Two rounds of invites were sent by email; if invitees did not respond after 2 weeks or decided not to participate, we sent a new invite to the next person registered on the database (demographically matched). A total of 35 people were invited to participate; 21 responded to indicate interest. Respondents were provided with full details about the research and invited to an informal telephone discussion with the interviewer $(\mathrm{HH})$ to discuss the research aims and procedures. Eighteen people took
Table 1 Characteristics of people registered on the RICOVR database at study commencement

n $\%$

\begin{tabular}{lcc|}
\hline Total: 2022 & & \\
Sex & & \\
Male & 271 & 13.4 \\
\hline Female & 1655 & 81.8 \\
\hline Undisclosed & 96 & 4.7 \\
\hline Age & & \\
\hline 18-24 & 28 & 1.4 \\
\hline $25-34$ & 219 & 10.8 \\
\hline $35-44$ & 575 & 28.4 \\
\hline $45-54$ & 686 & 33.9 \\
\hline $55-64$ & 337 & 16.7 \\
\hline 64 & 86 & 4.3 \\
\hline Undisclosed & 91 & 4.5 \\
\hline Ethnic background & & \\
\hline White & 1794 & 88.7 \\
\hline BAME & 120 & 5.9 \\
\hline Undisclosed & 108 & 5.3 \\
\hline
\end{tabular}

BAME, black, Asian and minority ethnic.

up this opportunity; all subsequently decided to proceed. Participants completed a written consent form returned via email before interview. Seventeen participants were residing in the UK and one was living in the USA. After interviewing 18 participants, the research team were satisfied that thematic saturation was reached ${ }^{21}$ and recruitment ceased.

\section{Patient and public involvement}

During the study design, the AWRC Public Involvement in Research Group ${ }^{22}$ reviewed study aims and all materials. The group provided feedback to refine documents including clarification of language in the participant information sheet, rewording of interview questions and the addition of information about support for carers in the postinterview support document.

\section{Interview procedures}

A semistructured interview guide (online supplemental file) was developed to elicit participants' stories about their lived experience of long COVID and the role of PA within that experience. Open questions explored four broad topic areas: (1) illness and recovery trajectory, (2) sources of support, (3) experiences of PA and (4) future priorities and concerns. All interviews were conducted during September and October 2020 via telephone with the exception of two interviews carried out using Zoom video conferencing to suit participants' needs. All interviews were conducted by $\mathrm{HH}$, an experienced female qualitative researcher in public health and exercise psychology. Interviews were audio-recorded and limited 
to a maximum of $45 \mathrm{~min}$ to limit any cognitive burden for participants. Participants were not reimbursed but were signposted to information detailing sources of support within and beyond the University should any distress have been caused by the interview.

\section{Data analysis}

All recordings were transcribed verbatim by a professional transcription service. Transcripts were sent to participants for review; one participant responded with clarifications which were included in our analysis. Reflexive thematic analysis with inductive, semantic coding ${ }^{23}$ was used to interpret the data. Consistent with recommendations, we did not set out to achieve intercoder reliability. ${ }^{24}$ Instead, multiple researchers coded the transcripts to encourage reflexivity and ensure our analysis considered different possible interpretations. Two researchers (HH and LK, both with postgraduate psychology qualifications, training and experience in qualitative interviewing) reviewed $50 \%$ of the transcripts each. HH and LK independently developed preliminary coding frameworks presenting initial themes, which they compared and refined with input from a third researcher (NK) who had read a cross section of the transcripts. Following discussion with a fourth researcher (RC), HH, LK and NK returned to the transcripts to sense-check candidate themes and ensure that they offered an appropriate representation of the data, at which point themes were defined and named.

\section{RESULTS}

\section{Participants}

Eighteen people took part in an interview (see table 2 for sample characteristics).

Four themes were identified: the interconnection of physical and psychological symptoms; lack of clear and consistent PA-related advice; learning to balance symptoms and activity; and adapting to an altered life. Themes are described below with illustrative participant quotes.

\section{Interconnection of physical and psychological symptoms}

Participants recounted their experiences of long COVID in detail, describing diverse individual illness trajectories and varied patterns of symptoms presenting throughout the body. All participants described significant debilitation, with their physical function drastically reduced. This meant several weeks, and in many cases months, of being virtually housebound. During this period, basic activities of daily living (ADLs) including self-care and housework became challenging or impossible, and formal exercise was unconceivable:

The slightest thing was an effort in a way I've never ever conceived before, it's the most fatigued I have ever been ... things like changing my bedding, I did in stages like one pillowcase and then later in the day I'd do another pillowcase, it was that sort of level of difficulty with day-to-day tasks. (IV2)
Table 2 Participant characteristics

\begin{tabular}{|c|c|c|c|c|}
\hline ID & Sex & $\begin{array}{l}\text { Age } \\
\text { group }\end{array}$ & Ethnic group & $\begin{array}{l}\text { Place of } \\
\text { residence }\end{array}$ \\
\hline 1 & Male & $55-64$ & White-Irish & UK \\
\hline 2 & Female & $45-54$ & $\begin{array}{l}\text { Asian or Asian } \\
\text { British - Indian }\end{array}$ & UK \\
\hline 3 & Male & $35-44$ & White-British & UK \\
\hline 4 & Male & $18-24$ & $\begin{array}{l}\text { Black or Black } \\
\text { British- } \\
\text { Caribbean }\end{array}$ & UK \\
\hline 5 & Male & $45-54$ & White-British & UK \\
\hline 6 & Male & $65-74$ & White-British & US \\
\hline 7 & Female & $25-34$ & $\begin{array}{l}\text { Mixed-White } \\
\text { and Asian }\end{array}$ & UK \\
\hline 8 & Female & $65-74$ & White-British & UK \\
\hline 9 & Male & $35-44$ & $\begin{array}{l}\text { Asian or Asian } \\
\text { British - Indian }\end{array}$ & UK \\
\hline 10 & Male & $65-74$ & White-British & UK \\
\hline 11 & Female & $18-24$ & White-British & UK \\
\hline 12 & Male & $18-24$ & White-British & UK \\
\hline 13 & Female & $65-74$ & White-British & UK \\
\hline 14 & Female & $55-64$ & White-British & UK \\
\hline 15 & Male & $45-54$ & White-Other & UK \\
\hline 16 & Female & $35-44$ & White-Other & UK \\
\hline 17 & Female & $35-44$ & White-British & UK \\
\hline 18 & Female & $45-54$ & $\begin{array}{l}\text { Asian or Asian } \\
\text { British - Indian }\end{array}$ & UK \\
\hline
\end{tabular}

It has affected me to the point of like debilitating ... I've had to contact the school and say I can't do the one-way system to drop off. So literally I drop my son off right outside the school so I don't have to walk the 10 minutes' walk around the one-way system. I can't do that. (IV7)

The combination of physical and cognitive symptoms added to an overall sense of debilitation:

So if I do something physical I suffer. If I walk I suffer in my legs. If I do something with my hands I suffer with my hands. If I start to think too much I then get a foggy head. If I type an email on the computer and it goes on too long, I then can't think enough to shut the computer down. (IV5)

Physical and psychological impacts of long COVID were interlinked. For some participants, prolonged and unexpected physical incapacitation had emotional implications, including lowered self-esteem, frustration and guilt about not being able to fulfil everyday responsibilities. Some participants believed that stress was a specific trigger for physical symptoms:

I'm the wrong generation to just not go to work. So I know I couldn't go to work but I felt guilty about not 
going to work ... once I knew every week that I had to be in touch I'd get really anxious because I knew I couldn't string a sentence together or even send a proper email. (IV14)

You see, stress brings it on and that makes it really bad. (IV13)

\section{Lack of clear and consistent PA-related advice}

Participants had varied expectations of how the healthcare system could support them with PA. Some were deterred from help-seeking by unhelpful responses or a perception that they did not meet the threshold for help. Others acknowledged the constraints facing clinicians, yet felt compelled to seek advice about unnerving symptoms. Questions about how to manage PA challenged the expertise of medical professionals, who lacked an evidence base for this novel condition and were unable to provide conclusive advice. Consequently, participants sought information and validation online. Social media forums provided a community that normalised the long COVID experience and provided coping strategies. In addition, most participants adopted a 'researcher' role, reading scientific articles and health resources to better understand their condition:

I think the GP that I've managed to speak to has been trying his best, but he is a little bit unsure himself you see .... the most things that have been useful are the support groups on Facebook, I hate to say it but that's where I've found most of my information. And then obviously I've been reading a lot of evidence papers as well. So I've been ... trying to form my own opinion and diagnosing myself. (IV18)

As a consequence, professional advice about PA often arrived after information had already been accessed online:

They [physiotherapist] offered loads of advice just about pacing really. But I think at that point because of all the communities that have sprung up everywhere online people had already been sharing this information. (IV3)

While information accessed online was broadly helpful, it lacked specificity for long COVID:

There's obviously people that have had ... different types of viruses, and they're all claiming that doing exercise and whatnot is harmful for your recovery. I'm not sure if you've heard of something called ME, a lot of people are stating ... don't do graded exercise ... don't do none of that ... (IV4)

Some participants also struggled with digesting online information, finding long periods of concentration difficult. One participant highlighted the challenges associated with critically appraising evidence:

... I don't really have any knowledge of just medical sciences or have the ability to just go and start reading the journals of the latest publications ... the common person can't do that. (IV12).

\section{Learning how to balance symptoms and activity}

Participants described a loss of freedom to engage with routine activities; any physical or cognitive activity resulted in the onset of fatigue. Some participants considered these relapses worthwhile, either because with each relapse followed a small perceived improvement in baseline function or because it was considered a price worth paying for the sense of normality, control and positive affect the activity provided:

So as much as I'm enjoying [walking the dog], it has the knock-on effect. But that is getting less and less, so the more I'm doing the better I'm feeling afterwards. I think [relapses are] all part of it, just got to get on with it and push myself a little bit harder and then hopefully I'll get better quicker. It doesn't put me off. (IV17)

Some participants were deterred from PA by seeing others with long COVID experience a symptom relapse. The severity and unpredictability of their own symptoms caused others to fear potential adverse events, along with the absence of any guarantee that permanent damage would not be caused by PA:

I read about pacing and I haven't tested myself, so I'm not exercising and I think that's a big thing for me ... So when I'm reading other people saying they get tired when they exercise, maybe that's put me off from trying that. Maybe it's the fear of not knowing. (IV9)

... I've always been one of those people that thinks well, you know, you push through it .... But this you just can't. And this is something that I'm becoming more afraid of that I think maybe I need to properly back off from as much daily activity as I can to recover from this because I'm scared that I will eventually end up as probably a $50 \%$ to a $60 \%$ of what I was previously, permanently, or for a longer term. (IV5)

Participants were especially discouraged from PA by symptoms such as breathlessness and heart palpitations. Where medical advice was sought or provided, this tended to err on the side of caution and thus reinforced decisions to avoid PA:

My heart rate being high is a worry. I do experience chest pain and constant tightness on my chest, which again is a worry. And I've never felt as if I could really push myself ... And my doctor has said ... well don't push it, you may do more harm than good by pushing too much. Which again doesn't help me an awful lot ... (IV1)

Most participants established personal strategies for managing PA based on trial and error. All described a limited energy reserve that must be used wisely, planning 
their days according to personal schedule and priorities. Activities tended to be selected based on their benefit to well-being and/or responsibilities, for example, walking, getting outdoors and fulfilling caring duties:

I have to try and think well if I need to be around to look after my kids or something in particular in a day I need to be very, very careful of what I do the day before. (IV5)

I do the physical things that look after my mental health. So going outside and getting some fresh air looks after my mental health, and it in doing so helps the other symptoms, if that makes sense. So I focus on those a lot. So on a sunny day I'll go outside, because blue skies do me the world of good. (IV7)

This process of pacing and energy conservation was not without challenges. Many participants expressed a desire for better monitoring and support to manage PA, and bespoke long COVID guidance for establishing a safe, consistent baseline for activity:

Everything that you read is pace yourself, pace yourself. But that's really hard to do, because until you've overdone it you don't know how much you can do without overdoing it, if you see what I mean, so learning by default. Which isn't the best way, but I guess what's enough for me might not be enough for somebody else. (IV8)

... what I found with the advice for chronic fatigue syndrome is there seems to be, I don't know, I'm kind of just assuming this and making it up but it seems that there's more of a standard pattern; whereas with this it seems that no two days are alike so it's really hard to find a baseline because it's so erratic. (IV3)

\section{Adapting to an altered life}

There is a clear sense that long COVID is experienced as life-altering. Many participants described a loss of 'self' and a substantial impact on their identity. Some participants made sense of this as a 'pre-COVID-19' and 'postCOVID-19' life, and others described it as a journey. While the prospect of permanent disablement was distressing for all, many older participants drew on life events such as previous illness to make sense of their current experience:

... I'm self-aware when it comes to my health and my mood and I think I'm just accepting of it rather than wanting to change it or be negative about it. (IV13)

In contrast, younger participants (eg, those aged 18-24 years) struggled with their reduced function:

I just want my life back, it's getting a bit tedious. I see myself just becoming a burden, I don't want to live my life like that. (IV4)

The majority of participants had been unable to resume activities that were previously central to their core identity (eg, a parent, an employee). Any activity that provided a sense of normality thus helped to refute the idea that this changed identity was permanent (a prognosis that was both feared and resisted). Participants for whom PA was a core feature of their self-concept previously referred to this as a strong motivator in their desire to improve functional capacity and resume PA:

I've been a runner and then a cyclist for many years so I had the intent of getting back in the walking. And then as soon as I could I got back in the cycling a little bit. (IV6)

I've always been physically active ... So it was somewhat testing myself, somewhat being hard headed and driven and also hoping that I'm actually fine, it's all over now and I can get back to playing basketball soon ... (IV15)

Some participants had reached a point of 'reluctant acceptance', not necessarily arrived at peacefully but through exasperation and for some, a degree of selfdefeat. Participants described needing to give themselves permission (or seeking it from others) to rest, and some described a shift in priorities:

I'm just desperate to get back to exercise but I've had to learn that I can't, and a lot of mindfulness and patience and... the supportive people around me just helping basically, just listening. (IV3)

... I feel there's an opportunity for change. I might reduce my hours going forward. It's difficult but I might try and balance my work-life balance a bit more and pace myself. (IV9)

Family and friends played a significant role in participants' 'journeys'. While participants' symptoms were severe and physical function was most disrupted, friends and family acted as informal carers, supporting self-care activities such as cooking. They also provided emotional support, although as with medical professionals, this was sometimes contingent on an understanding and awareness of long COVID that developed gradually. Over time, family and friends became important PA companions, often adjusting their own PA behaviour to match the level of the person with long COVID and providing a reassurance that fostered confidence in activities such as walking:

I started going out every day and trying to do a bit more of a walk at home where it was relatively safe, my mum was there, she would walk with me and look after me. (IV11)

\section{DISCUSSION}

Resuming and maintaining 'normal' activity

Our findings illustrate the impact of long COVID on the energy reserves of individuals, which is consistent with previous reports. ${ }^{10}{ }^{11}$ Our study highlights the importance of activities of daily living (ADLs (eg, housework, gardening) and outdoor activity to the normality and mental health of people with long COVID interviewed. 
ADLs have been defined as fundamental skills required for independent living ${ }^{25}$ and are often used to assess physical function. Participants prioritised and selected these activities based on their individual meaning, balancing what was physically possible against what provided the biggest return on investment in terms of feeling normal, engaged in family life or what boosted their mood.

Our findings indicate that people experiencing long COVID need better support to manage their symptoms, especially fatigue, while also helping them safely pursue the potential benefits of PA. As in previous research, ${ }^{11}$ participants reported that guidance about PA was not always tailored to the complexity of long COVID. In particular, they lacked support on how to establish a baseline and upper threshold for activity which accommodated the erratic relapse-recovery cycle common to our participants' experience. Our research suggests that pacing needs to be individualised, considering biographical factors such as life-stage as well as current physical function and activity history. Many people will also require monitoring (either via professional or self-monitoring tools) to provide reassurance about the safety of PA while experiencing other symptoms like rapid heartbeat or breathlessness.

Our findings reflect concerns regarding the potential risk of long-term damage associated with postexertion malaise and PA. Participants differed in their attitudes towards relapse, some believing they were constructive to recovery, whereas others feared danger to longterm health. This paradoxical role of PA in relation to relapse and recovery reflects previous qualitative studies involving people with physically limiting conditions such as multiple sclerosis. ${ }^{26}$ Parallels have been drawn between long COVID and myalgic encephalomyelitis (ME) and/or chronic fatigue syndrome (CFS) ${ }^{27}$ Recently, the National Institute for Health and Care Excellence withdrew a recommendation to prescribe graded exercise therapy for patients with ME/CFS following concerns it could cause harm. ${ }^{28}$ It is imperative to establish consensus, adding to what is already known ${ }^{17}$ regarding PA-related advice specifically for people with long COVID, including the identification of individual phenotypes for whom PA might or might not add value to their recovery.

\section{Access to information and the role of the internet}

For the majority of our participants, online long COVID communities provided opportunities to relate and empathise with others. ${ }^{2} 1011$ Online communities pool collective knowledge derived from the lay expertise of members. ${ }^{29}$ Information being shared is thus vetted and validated by the online community itself, ${ }^{30} 31$ and such groups can provide access to rapidly changing information that is inaccessible or unavailable offline. ${ }^{32}{ }^{33}$ Advice about PA was accessed online much quicker than it was cascaded via medical professionals. The novelty of long COVID, however, meant that the lay expertise of members was sometimes dependent on learning from patients with other apparently similar conditions. In the case of graded exercise therapy, this had potential to cause confusion where advice was controversial or disputed by some patients. Most participants also experimented with pacing and graded exercise without support from a health professional, risking potential damage to their health.

\section{Influence of psychological characteristics on PA behaviour}

Previous research involving people with long COVID has reported a substantial impact on identity. ${ }^{10} 11$ Our study extends these findings; people for whom PA was a core aspect of their identity pre-COVID-19 were more inclined to push themselves physically, willing to risk relapses or view them as constructive. Their mental health was also more contingent on being able to undertake PA. PA identity has previously been associated with commitment, ability and self-regulation, with research suggesting that identity-behaviour discrepant situations can create negative affect. ${ }^{34}$ Further research could explore the relationship between PA identity and physiological and psychological responses to exertion and relapses in people with long COVID.

The common-sense model (CSM) of self-regulation ${ }^{35}$ could provide a useful theoretical framework for understanding PA behaviours in people with long COVID. The model illustrates how deviations from 'normal self' (eg, onset of symptoms and disruption of function) interact with illness beliefs (eg, drawing on past illness experiences) to appraise the threat level of long COVID symptoms. This results in the activation of treatment action plans (in this case, PA choices and behaviours) that are mediated by social influences (eg, family/friends, mass media). ${ }^{36}$ The CSM highlights a number of attributes that influence appraisal of health threats and subsequent behaviours, including expectations about the timeline for a given illness and perceived efficacy of self-management behaviours. In our study, these factors affected participants' likelihood of continuing to engage in PA; participants who felt that PA had a positive effect were more committed to maintaining PA. In contrast, some participants re-evaluated their PA behaviour over time, reducing PA when symptoms continued longer than expected or if they perceived PA to be harmful.

While the aim of our study was not to undertake a comparative analysis, we were alerted to potentially important age-related differences. Specifically, we noted that among younger participants the debilitating physical symptoms of long COVID appeared to have a particularly negative impact on participants' sense of self, and for these participants, adjusting to an uncertain future presented significant psychological struggle. Future work could examine the particular psychological-related and identity-related challenges of long COVID experienced by differing age cohorts. Sociological theories of illness including 'biographical disruption ${ }^{, 37}$ might offer a potentially useful explanatory framework for such work. 


\section{Implications for long COVID rehabilitation}

The range of symptoms, severity, frequency and duration associated with long COVID ${ }^{38}$ presents significant challenges for the publication of precise recommendations for PA in people with long COVID. Recommendations need to be tailored to individuals' clinical status and in some cases will require medical assessment by a specialist.

Our findings endorse ongoing efforts to establish holistic models of care that address both the physical and psychological impact of the condition. ${ }^{39}$ They also highlight the limited capacity of primary care to provide PA-specific support. We agree with calls for multidisciplinary work to support people with long COVID,${ }^{40}$ highlighting the potential role of sports medicine and the need for collaboration between centres of well-being, behavioural science and professionals from a range of medical specialties.

\section{Limitations}

In our study, 17 out of 35 people invited chose not to participate. We did not ask non-responders to provide a reason for declining participation, and thus cannot speculate on their personal choices, but the scope of our study indicates a potential for response bias towards people with a particular interest in PA. Qualitative research of this kind is typically based on small samples and is not intended to be generalisable, seeking instead to provide trustworthiness and sufficient context to allow readers to make their own transferability judgement. ${ }^{41}$ To date, inconsistent diagnoses of long COVID have made it difficult to ascertain the demographic profile of people with long COVID at a population level, with women disproportionately represented in symptom studies ${ }^{42}$ and qualitative research ${ }^{1011}$ along with people of higher educational background. ${ }^{10}$ We took steps to achieve a diverse sample in terms of age, gender and ethnicity, but did not collect information on socioeconomic status or geographical characteristics of participants, so are unable to draw firm conclusions about how these factors may influence our findings. Nevertheless, our participants were recruited from a research interest database indicating a level of engagement and access to online research, and our sample might not be representative of the long COVID population as a whole. Inclusion of people from digitally excluded populations ${ }^{43}$ and a wide range of demographic profiles is important for future research and a key factor in providing equity of access to long COVID support.

\section{CONCLUSIONS}

This study provides insight into the challenges of managing PA alongside the extended symptoms associated with long COVID. Findings highlight the need for greater clarity and tailoring of PA-related advice for people with long COVID and improved support to resume activities important to individual well-being.

Acknowledgements The authors thank all participants of this study for sharing their time and experiences.
Contributors RC initiated the idea for the study. HH designed the protocol and secured ethics for the study with support from RC. NK undertook stratification of database participants. HH undertook recruitment including invitations to take part, provision of participant information and collecting written informed consent. $\mathrm{HH}$ carried out all interviews. HH and LK undertook initial data analysis and developed preliminary coding frameworks. HH, LK and NK reviewed and refined themes with oversight from RC. HH prepared the manuscript, and all authors edited and revised the final version.

Funding The authors have not declared a specific grant for this research from any funding agency in the public, commercial or not-for-profit sectors.

Competing interests None declared.

Patient consent for publication Not required.

Provenance and peer review Not commissioned; externally peer reviewed.

Data availability statement Complete transcripts are not available as they pose a risk to participant confidentiality. All other study materials are available upon reasonable request.

Supplemental material This content has been supplied by the author(s). It has not been vetted by BMJ Publishing Group Limited (BMJ) and may not have been peer-reviewed. Any opinions or recommendations discussed are solely those of the author(s) and are not endorsed by BMJ. BMJ disclaims all liability and responsibility arising from any reliance placed on the content. Where the content includes any translated material, BMJ does not warrant the accuracy and reliability of the translations (including but not limited to local regulations, clinical guidelines, terminology, drug names and drug dosages), and is not responsible for any error and/or omissions arising from translation and adaptation or otherwise.

Open access This is an open access article distributed in accordance with the Creative Commons Attribution Non Commercial (CC BY-NC 4.0) license, which permits others to distribute, remix, adapt, build upon this work non-commercially, and license their derivative works on different terms, provided the original work is properly cited, appropriate credit is given, any changes made indicated, and the use is non-commercial. See: http://creativecommons.org/licenses/by-nc/4.0/.

ORCID iD

Helen Humphreys http://orcid.org/0000-0003-3474-2793

\section{REFERENCES}

1 WHO. WHO coronavirus disease (COVID1-19) Dashboard, 2019. Available: https://covid19.who.int

2 Maxwell E. Living with Covid19: a dynamic review of the evidence around ongoing Covid19 symptoms (often called long Covid) NIHR Cent Engagem Dissem; 2020: 1-29.

3 Assaf G, Davis H, McCorkell L. What does COVID-19 recovery actually look like? Patient Led Research; 2020. https://patientresea rchcovid19.com/research/report-1/ [Accessed 16 Nov 2020].

4 Davis HE, Assaf GS, McCorkell L. Characterizing long COVID in an international cohort: 7 months of symptoms and their impact. medRxiv 2020.

5 Townsend L, Dyer AH, Jones $\mathrm{K}$, et al. Persistent fatigue following SARS-CoV-2 infection is common and independent of severity of initial infection. PLoS One 2020;15:e0240784.

6 Goërtz YMJ, Van Herck M, Delbressine JM, et al. Persistent symptoms 3 months after a SARS-CoV-2 infection: the postCOVID-19 syndrome? ERJ Open Res 2020;6:00542-2020.

7 Office for National Statistics. The prevalence of long COVID symptoms and COVID-19 complications. Available: https://www.ons. gov.uk/news/statementsandletters/theprevalenceoflongcovidsymp tomsandcovid19complications [Accessed 19 Jan 2021].

8 Dennis A, Wail M, Kapur S. Multi-Organ impairment in low-risk individuals with long COVID. MedRxiv 2020.

9 Long covid and self-help pacing groups - getting by with a little help from our friends. Available: https://blogs.bmj.com/bmj/2020/09/29/ long-covid-and-self-help-pacing-groups-getting-by-with-a-littlehelp-from-our-friends/ [Accessed 25 Nov 2020].

10 Ladds E, Rushforth A, Wieringa S, et al. Persistent symptoms after Covid-19: qualitative study of 114 'long Covid' patients and draft quality principles for services. BMC Health Serv Res 2020;20:1-3.

11 Kingstone T, Taylor AK, O'Donnell CA, et al. Finding the 'right' GP: a qualitative study of the experiences of people with long-COVID. BJGP Open 2020;4. doi:10.3399/bjgpopen20X101143. [Epub ahead of print: 1512 2020]. 
12 Your COVID recovery. Available: www.yourcovidrecovery.nhs.uk [Accessed 19 Jan 2021].

13 Royal College of Occupational Therapists. How to conserve your energy, 2020. Available: https://www.rcot.co.uk/conserving-energy [Accessed 19 Jan 2021].

14 Fraser E. Long term respiratory complications of covid-19. BMJ 2020;370:m3001-2.

15 Kennedy FM, Sharma S. COVID-19, the heart and returning to physical exercise. Occup Med 2020;70:467-9.

16 Woods JA, Hutchinson NT, Powers SK, et al. The COVID-19 pandemic and physical activity. Sports Medicine and Health Science 2020;2:55-64.

17 Greenhalgh T, Knight M, A'Court C, et al. Management of post-acute covid-19 in primary care. BMJ 2020;370:m3026.

18 Research and innovation for post Covid-19 rehabilitation (RICOVR). Available: https://www.shu.ac.uk/research/specialisms/advancedwellbeing-research-centre/ricovr

19 NICE, SIGN, RCGP. COVID-19 guideline scope: management of the long-term effects of COVID-19, 2020. Available: https://www.nice1. org.uk/guidance/gid-ng10179/documents/final-scope [Accessed 9 Nov 2020]

20 Office for national statistics (August 2020). Available: https://www. ethnicity-facts-figures.service.gov.uk/uk-population-by-ethnicity/ national-and-regional-populations/population-of-england-and-wales/ latest [Accessed Sep 2020].

21 Saunders B, Sim J, Kingstone T, et al. Saturation in qualitative research: exploring its conceptualization and operationalization. Qual Quant 2018;52:1893-907.

22 . Available: http://www.awrc-publicinvolvementinresearchgroup.co. uk/

23 Braun V, Clarke V. Successful qualitative research: a practical guide for beginners. SAGE, 2013.

24 Braun V, Clarke V. What can 'thematic analysis' offer health and wellbeing researchers? Int J Qual Stud Health Well-being 2014;9:26152.

25 Katz S. Assessing self-maintenance: activities of daily living, mobility, and instrumental activities of daily living. J Am Geriatr Soc 1983;31:721-7

26 Adamson BC, Adamson MD, Littlefield MM, et al. 'Move it or lose it': perceptions of the impact of physical activity on multiple sclerosis symptoms, relapse and disability identity. Qual Res Sport Exerc Health 2018;10:457-75.

27 Islam MF, Cotler J, Jason LA. Post-Viral fatigue and COVID-19: lessons from past epidemics. Fatigue: Biomedicine, Health \& Behavior 2020;8:61-9.

28 NICE. National Institute for Health and Care Excellence. Myalgic encephalomyelitis (or encephalopathy)/chronic fatigue syndrome: diagnosis and management. Draft for consultation, 2020. Available: https://www.nice.org.uk/guidance/indevelopment/gid-ng10091/ consultation/html-content-2 [Accessed 9 Nov 2020].

29 Allen C, Vassilev I, Kennedy A, et al. Long-Term condition selfmanagement support in online communities: a Meta-Synthesis of qualitative papers. J Med Internet Res 2016;18:e61.

30 Greene JA, Choudhry NK, Kilabuk E, et al. Online social networking by patients with diabetes: a qualitative evaluation of communication with Facebook. J Gen Intern Med 2011;26:287-92.

31 Zhang Y, He D, Sang Y. Facebook as a platform for health information and communication: a case study of a diabetes group. $J$ Med Syst 2013;37:9942.

32 Hadert A, Rodham K. The invisible reality of arthritis: a qualitative analysis of an online message board. Musculoskeletal Care 2008;6:181-96.

33 Mo PKH, Coulson NS. Are online support groups always beneficial? A qualitative exploration of the empowering and disempowering processes of participation within HIV/AIDS-related online support groups. Int J Nurs Stud 2014;51:983-93.

34 Rhodes RE, Kaushal N, Quinlan A. Is physical activity a part of who I am? A review and meta-analysis of identity, schema and physical activity. Health Psychol Rev 2016;10:204-25.

35 Leventhal H, Meyer D, Nerenz D. The common sense representation of illness danger. Contributions to Medical Psychology 1980;2:7-30.

36 Leventhal H, Phillips LA, Burns E. The Common-Sense model of self-regulation (CSM): a dynamic framework for understanding illness self-management. J Behav Med 2016;39:935-46.

37 Bury M. Chronic illness as biographical disruption. Sociol Health \& IIIness 1982;4:167-82.

38 Gorna R, MacDermott N, Rayner C, et al. Long COVID guidelines need to reflect lived experience. Lancet 2021;397:455-7.

39 NHS England. National guidance for post-COVID syndrome assessment clinics, 2020NHS England and NHS Improvement. Available: https://www.england.nhs.uk/coronavirus/wpcontent/ uploads/sites/52/2020/10/C0840_PostCOVID_assessment_clinic_ guidance_5_Nov_2020.pdf [Accessed 17 Nov 2020].

40 Faghy MA, Ashton RE, Maden-Wilkinson TM, et al. Integrated sports and respiratory medicine in the aftermath of COVID-19. Lancet Respir Med 2020;8:852.

41 Korstjens I, Moser A. Series: practical guidance to qualitative research. Part 4: Trustworthiness and publishing. Eur J Gen Pract 2018;24:120-4.

42 Sudre $\mathrm{CH}$, Murray B, Varsavsky T. Attributes and predictors of LongCOVID: analysis of COVID cases and their symptoms collected by the Covid Symptoms Study App. medRxiv 2020.

43 NHS Digital. Digital inclusion for health and social care: what we mean by digital inclusion. Available: https://digital.nhs.uk/about-nhsdigital/our-work/digital-inclusion/what-digital-inclusion-is [Accessed 9 Nov 2020]. 